\title{
Human Papilloma Virus Genotype Distribution in Women with Cervical Intraepithelial Neoplasia
}

\author{
(1) Mehmet BÜLBÜL, ${ }^{a}$ \\ - Berna DiLBAZ, \\ (1) Bilge AYDIN TÜRK, ${ }^{c}$ \\ (1) Filiz HATIPOĞLU, ${ }^{a}$ \\ (D) Esra BOYAR ${ }^{d}$
}

aDepartment of Obstetrics and Gynecology, Adıyaman University Faculty of Medicine,

bDepartment of Obstetrics and Gynecology, Health Sciences University

Etlik Zübeyde Hanım Health Practice and

Research Hospital,

Ankara

'Department of Pathology,

Adıyaman University Faculty of Medicine,

${ }^{d}$ Clinic of Obstetrics and Gynecology,

Adıyaman University Training and

Research Hospital,

Adıyaman

Received: 07.09.2018

Accepted: 03.10.2018

Available online: 25.10 .2018

\section{Correspondence:}

\section{Mehmet BÜLBÜL}

Adıyaman University Faculty of Medicine,

Department of Obstetrics and Gynecology, Adiyaman, TURKEY

mehmetbulbulmd@gmail.com

Copyright @ 2018 by Türkiye Klinikleri

\begin{abstract}
Objective: The aim of this study is to identify the prevalence of oncogenic human papillomavirus (HPV) genotypes in women with abnormal smear or cervical HPV infection and histopathological examination of colposcopy-guided biopsies in women with HPV positivity in a southeastern city of Turkey. Material and Methods: One-hundred eighty-nine women who were referred for either HPV positivity or an abnormal smear result were recruited to the study. The prevalence of oncogenic and non-oncogenic HPV genotypes was analyzed according to the histopathological diagnosis of the specimens obtained via cervical smear and colposcopy-guided biopsies. Results: Out of 189 patients, $36(19,0 \%)$ had an abnormal smear result and $153(81,0 \%)$ had a positive HPV test. Out of 153 patients, 33,9\% (n=64) were positive for HPV 16 and/or 18 and 47.1 $(n=89)$ were positive for other HPV genotypes. While 112 patients had positivity for one HPV genotype $21.7 \%$ were positive for 2 or more HPV genotypes. The most frequent HPV genotypes were HPV 16 (24.2\%), HPV 18 (8.2\%), HPV 51 (7.8\%), HPV 39 (5.9\%) and HPV 53 (4.6\%). The highest prevalence of HPV16-18 was in the 30-49 age group. HPV 16 and 18 positivity were recorded in $20.2 \%$ of the cases with benign pathology while the prevalence was $34.7 \%$ in CIN I, $57.1 \%$ in CIN II-III and 100\% in cases with invasive cervical carcinoma. Conclusion: HPV 16 and 18 were the most prevalant oncogenic HPV genotypes in the studied patient group and their presence was related with the severity of the cervical pathology.
\end{abstract}

Keywords: Cervical intraepithelial neoplasia; colposcopy; human papilloma virus

ervical cancer with half million newly diagnosed cases annually, is the fourth must frequent cancer among women in the world. ${ }^{1}$ According to GLOBOCAN 2012 country data cervical cancer is the $12^{\text {th }}$ most common cancer and with a mortality rate of 1.7 per hundred thousand ranks as the $15^{\text {th }}$ cause of death among Turkish women. ${ }^{2}$ Persistent infection with human papillomavirus (HPV) is now known to be a well-established cause of cervical cancer and cervical intraepithelial neoplasias (CIN). ${ }^{3-5}$ As Worldwide, human papilloma virus (HPV) is detected in more than $99 \%$ of cervical cancers. HPV has more than 116 different genomic types of which 40 are responsible for anogenital infections. Moreover, 14 of these types especially HPV types 16 and 18 are regarded as high-risk genotypes as they are responsible for malignant progression to cervical cancer (HPV types 16, 18, 31, 33, 35, 39, 45, 51, 52, 56, 58, 59, 66, and 68$)$. HPV-16 being the most carcinogenic genotype is associated with approximately $60 \%$ of all cervical cancers, followed by HPV-18 that is present in around $10 \%$ to $15 \%$ of the cases. ${ }^{6}$ 
Cervical cancer screening programmes aim early detection and treatment of precancerous lesions that might progress to cervical cancer. Cervical cancer screening programmes have been traditionally based on Pap Smear since the mid1950s. The difficulties related to the screening programmes based on Pap smear is the need for highly trained cytopathologists, and the well-known problem of interpathologist interpretive variability and false-positivity due to various other inflammatory conditions or false-negativity related with the sampling technique. ${ }^{7}$ Based on the widely-known etiological relationship between progression of cervical cancer and HPV, HPV testing using PCR has become a standart screening method for diagnosis of cervical HPV infection. Primary HPV testing is proposed to replace national Pap smear screening programmes in many countries as it is cost-effective and can allow a safe screening interval. ${ }^{8,9}$

The population of Turkey is approximately 82 million, of which around 21 million are women aged 15-49 years old. ${ }^{10}$ The south-eastern city that the study was conducted has a population of 610000 and there is only one state institution; the university hospital serving to the whole population. All the patients are referred to this hospital.

Objectives: The aim of this study is to identify the prevalence of oncogenic HPV genotypes in women with abnormal smear or cervical HPV infection and histopathological examination of colposcopy-guided biopsies in women with HPV positivity in a southeastern city of Turkey.

\section{MATERIAL AND METHODS}

Between April 2014 and June 2017, one-hundred and eighty-nine patients who were referred to Adiyaman University Hospital Department of Colposcopy for either HPV positivity during HPV screening at the primary health care facilities $(\mathrm{n}=15381.0 \%)$ or had an abormal smear $(\mathrm{n}=36$, $19.0 \%$ ) result during their follow-up at the university clinic were recruited to the study (Figure 1).

The inclusion criteria was either having an abnormal cervical smear result or having HPV positivity. The patients who had a benign cervical

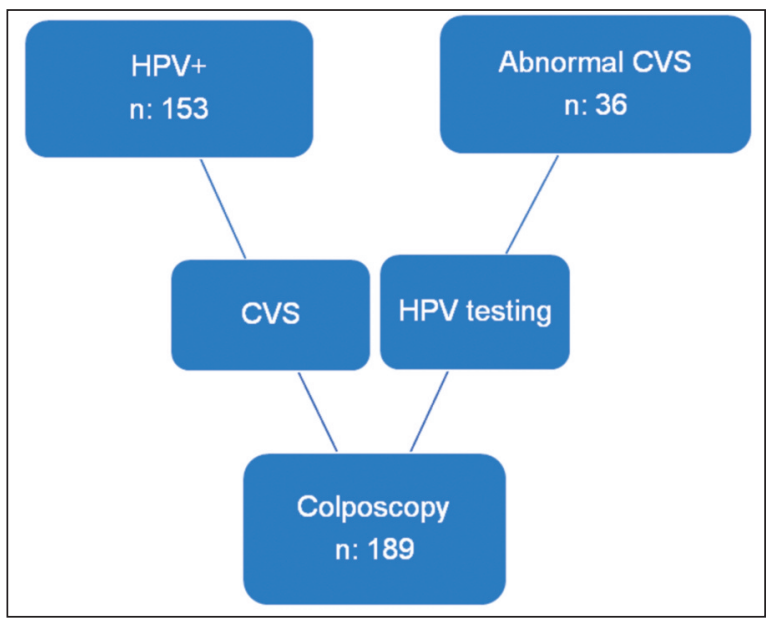

FIGURE 1: Study Flow chart.

cytology and are negative for HPV were excluded from the study. The study was approved by the Ethical Committee of Adiyaman University School of Medicine (Decision number: 2017/9-5).

All the patients were informed about the study and the patients who accepted to take part in the study gave an informed signed consent. A patient form was filled in for each patient in order to record the demographic data and obstetric history of the patient.

The cytological samples obtained by cervical swabs were liquid-based Pap smears and the results were classified according to the 2001 Bethesda system. Cervical smear was performed on all the patients who did not have one and HPV test was performed on the patients who did not have an HPV test result. HPV testing was carried out using Anyplex ${ }^{\text {TM }}$ II HPV28 Dedection-CFX96TM RealTime PCR System (Bio-Rad Laboratories, Hercules, CA). As a result, all the patients had HPV testing and a histopathological evaluation of the cervical smear.

All the patients had a colposcopic examination followed by colposcopy-guided biopsy. Using a Leica Colposcope (Leica Microsystems Ltd Business Unit SM CH-9435 Heerbrugg, Switzerland), the uterine cervix and specifically the transformation zone (squamo-columnar junction) was visualized. Acetic acid (3\% to 5\%) and Lugol's iodine was applied to identify potential lesions and vascular 
atypia was investigated. Colposcopies and biopsies were carried-out by the same researcher Colposcopy-guided biopsies were taken and sent for histopathological evaluation. The pathologist was blinded to the HPV test results of the patient. The histopathological findings of the colposcopy biopsy were recorded.

The histopathological results of the colposcopy-guided biopsies were evaluated according to the presence of oncogenic HPV types (HPV 16, $18,39,51,53)$ and other HPV genotypes.

Statistical Analysis: Statistical analysis was performed using SPSS 15 for Windows (Statistical Package for the Social Sciences software version 15). Continuous variables were given in means $\pm S D$ standard deviations. Comparisons categoric variables were compared with Chi-square test. The level of statistical significance was defined as $\mathrm{p}<$ 0.05 .

\section{RESULTS}

One hundred and eighty-nine patients were recruited to the study, of which $36(19.0 \%)$ had an abnormal smear result and $153(81.0 \%)$ had a positive HPV test. Out of 153 patients, 33.9\% ( $\mathrm{n}=64)$ were positive for HPV 16 and/or 18 and 47.1 (n=89) were positive for other HPV genotypes. The main age, BMI and median gravidy and parity of the patients were $42.71 \pm 10.58,28.79 \pm 3.02,4(\mathrm{R}=0-15), 3$ $(\mathrm{R}=0-13)$ respectively. While 11 patients $(5.8 \%)$ were nulliparous, $73.6 \%(\mathrm{n}=139)$ had at least one vaginal delivery and $20.6 \%(n=39)$ had a cesarean section. The mean age at menarche and first coital age were $13.4 \pm 1.31$ and $19.37 \pm 4.34$ respectively and $82.5(\mathrm{n}=156) \%$ of the patients had only one partner. The median number of coital act per week was 2 ( $R=0-7)$. Twenty-five percent of the patients $(n=48)$ were smokers. When the contraceptive choice of the patients were analyzed; forty $(21.2 \%)$ of the patients were not using any contraceptive method while 32.3\% had an IUD inserted, 5.8\% had a tubal ligation and $9.5 \%$ were on combined oral contraceptives. Only $8.5 \%$ were using a condom while $18.5 \%$ were using withdrawal as a contraceptive method. The patients were then analyzed in three groups; patients with 1) HPV positivity for oncogenic genotypes, 2) HPV positivity for nononcogenic HV genotypes 3) HPV negative patients. The demographic features of these three groups showed no statistically significant difference (Table 1). The highest prevalence of HPV16-18 was in the 30-49 age group (Figure 2).

The cervical smear (CS) results of all patients were evaluated. Out of 189 patients, 10 had benign pathologies on histopathological examination of the CS, 38 (21.1\%) were found to have infection while one had an atrophic smear result. The results in the remaining patients were as follows: ASC-US ( $\mathrm{n}=64,33.9 \%)$, ASC-H ( $\mathrm{n}=18,9,5 \%)$, LSIL ( $\mathrm{n}=50$, $26.5 \%)$, HSIL ( $\mathrm{n}=4,2,1 \%)$, AGC $(\mathrm{n}=4,2,15 \%)$.

While forty-four of these patients (44/49, $89.8 \%$ ) had a benign CS result but a positivity for oncogenic HPV, five $(5 / 49,10.2 \%)$ had a positive test for non-oncogenic types. Out of 189 patients, $19 \%$ had a negative result for HPV, $7.4 \%$ were positive for non-oncogenic HPV genotypes, $73.6 \%$ had at least one oncogenic HPV (Table 2). Moreover, $59.3 \%(\mathrm{n}=112)$ had positivity for one HPV genotype while $21.7 \%(n=41)$ were positive for 2 or more HPV genotypes. The most frequent HPV genotypes were HPV 16 (24.2\%), HPV 18 (8.2\%), HPV 51 (7.8\%), HPV 39 (5.9\%) and HPV 53 (4.6\%) (Figure 3).

The HPV positivity was analyzed according to the histopathological results of the cervical smear; out of the 49 patients who were reported to have a benign histopathology 5 (10.2\%) had non-oncogenic HPV genotypes while 44 had a positive test for oncogenic HPV. When the histopathological evaluation of the cervical smears were matched with the HPV test results, $64.1 \%$ of the cases with ASC-US, $83.3 \%$ of the cases with ASC-H, $66 \%$ of the cases with LSIL and $100 \%$ of the cases with HSIL had oncogenic HPV genotype positivity (Table 2).

All the 189 patients who had undergone colposcopy-guided biopsy 64 (33.9\%) had HPV16 and/or 18 positivity while $47.1 \%(n=89)$ had other HPV genotypes and 19\% $(n=36)$ had an abnormal smear. Histopathological evaluation of the col- 
TABLE 1: The demographic features of the patients compared according to the HPV positivity status ( $n=189)$.

\begin{tabular}{|c|c|c|c|c|c|}
\hline & & Nononcogenic HPV n=14 & Oncogenic HPV n=139 & HPV negative $n=36$ & $\mathrm{p}$ \\
\hline Age $($ Mean $\pm S D)$ & & $46.1 \pm 13.5$ & $41.8 \pm 10.1$ & $44.8 \pm 11.1$ & 0.130 \\
\hline Height (Mean $\pm S D)$ & & $162.4 \pm 2.1$ & $162.7 \pm 3.7$ & $162.0 \pm 4.1$ & 0.516 \\
\hline Weight (Mean \pm SD) & & $72.5 \pm 4.9$ & $76.7 \pm 9.0$ & $75.1 \pm 8.3$ & 0.307 \\
\hline BMI $($ Mean \pm SD) & & $27.5 \pm 2.2$ & $28.9 \pm 3.1$ & $28.6 \pm 2.8$ & 0.503 \\
\hline Gravidy (Median (Min-Max)) & & $6(1-11)$ & $4(0-15)$ & $4(0-10)$ & 0.341 \\
\hline Parity (Median (Min-Max)) & & $4(1-9)$ & $3(0-13)$ & $3(0-7)$ & 0.445 \\
\hline Abortion (Median (Min-Max)) & & $1(0-2$ & $1(0-10)$ & $1(0-7)$ & 0.837 \\
\hline Age at marriage $\left(\mathrm{Mean}_{ \pm} \mathrm{SD}\right)$ & & $18.9 \pm 4.2$ & $19.4 \pm 4.4$ & $19.5 \pm 4.4$ & 0.747 \\
\hline Age of menarche $($ Mean $\pm S D)$ & & $13.3 \pm 1.4$ & $13.5 \pm 13$ & $13.2 \pm 1.5$ & 0.313 \\
\hline No of sexual act per week (Median (Min-Max) & & $2(0-5)$ & $2(0-7)$ & $2(0-7)$ & 0.846 \\
\hline Number of partners (Median (Min-Max)) & & $1(1-2)$ & $1(1-4)$ & $1(1-2)$ & 0.599 \\
\hline Smoking (Median (Min-Max)) & & $3(23.1)$ & $35(27.6)$ & $10(29.4)$ & 0.910 \\
\hline \multirow[t]{7}{*}{ Contraceptive method currently used (N. \%) } & None & $1(7.1)$ & $28(20.1)$ & $11(30.6)$ & \\
\hline & IUD & $7(50.0)$ & $46(33.1)$ & $8(22.2)$ & \\
\hline & TL & $0(0.0)$ & $9(6.5)$ & $2(5.6)$ & \\
\hline & $\mathrm{COC}$ & $0(0.0)$ & $15(10.8)$ & $3(8.3$ & \\
\hline & Injectable & $0(0.0)$ & $6(4.3)$ & $2(5.6)$ & 0.138 \\
\hline & Condom & $1(7.1)$ & $14(10.1)$ & $1(2.8)$ & \\
\hline & Withdrawal & $535.7)$ & $21(15.1)$ & $9(25.0)$ & \\
\hline
\end{tabular}

BMI: Body Mass Index; IUD: Intrauterine Device; TL: Tubal Ligation; COC: Combined Oral Contraception; C/S: Cesarean Section.

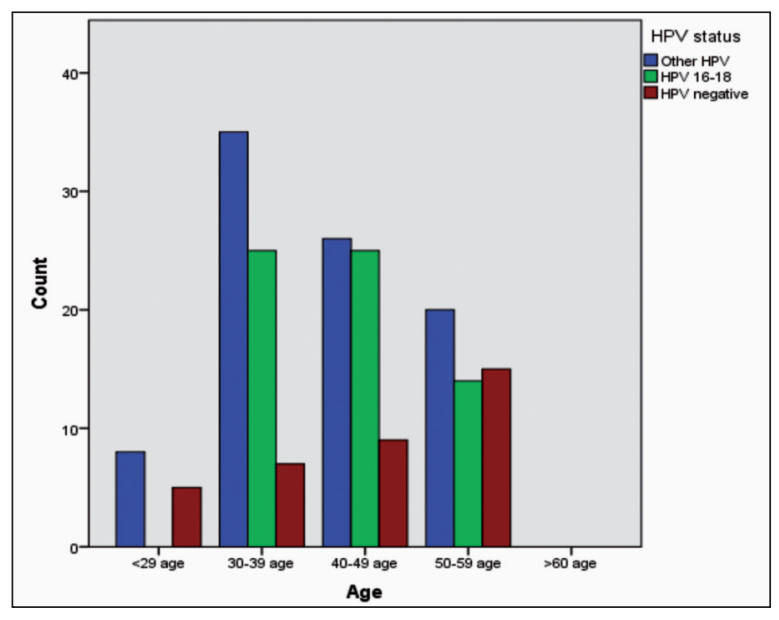

FIGURE 2: Prevalence of HPV genotypes according to the age groups.

poscopy-guided biopsies of the patients showed that $49.7 \%$ had benign pathology while $26 \%$ had CIN I, 22.2\% CIN II-III, while four cases were found to have invasive cervical cancer. Forty-nine percent of the cases who were reported to have benign cervical smear were found to have CIN I and CIN II-III when a colposcopy-guided biopsy was taken. Comparison of the histopathological exam- ination of the cervical smears with colposcopy guided- biopsies is shown in (Table 3).

When the prevalence of oncogenic and nononcogenic HPV genotype positivity in the benign cases and cases with CIN I, CIN II-III and the cases with invasive cervical cancer that were confirmed with colposcopy-guided biopsies were compared, the prevalence of oncogenic HPV genotypes were statistically significantly higher in all groups (Table 2). HPV 16 and 18 positivity was recorded in $20.2 \%$ of the cases with benign pathology while the prevalence was $34.7 \%$ in CIN I, $57.1 \%$ in CIN II-III and $100 \%$ in cases with invasive cervical carcinoma. Seven patients who had CIN I and two patients who had CIN II-III were HPV negative (Table 3). The presence of single HPV genotype was statistically significantly higher in benign, CIN I, CIN II-II and invasive cervical carcinoma cases $(\mathrm{p}<0.001)$.

\section{DISCUSSION}

Turkey's nationwide HPV DNA screening program aims to screen women over 30 at the primary health-care facilities and collect the data at the $\mathrm{Na}$ - 
TABLE 2: The distribution of HPV positivity in patients with abnormal smear and colposcopy-guided biopsies results.

\begin{tabular}{|c|c|c|c|c|c|}
\hline & & Non-oncogenic HPV n (\%) & Oncogenic HPV* $n(\%)$ & HPV negative n (\%) & $\mathbf{P}$ \\
\hline & Benign* & $5(10.2)$ & $44(89.8)$ & $0(0.0)$ & \\
\hline & ASC-US & $5(7.8)$ & $41(64.1)$ & $18(28.1)$ & \\
\hline & ASC-H & $1(5.6)$ & $15(83.3)$ & $2(11.1)$ & \\
\hline \multirow[t]{6}{*}{ Smear } & LSIL & $3(6.0)$ & $33(66.0)$ & $14(28.0)$ & 0.012 \\
\hline & HSIL & $0(0.0)$ & $4(100.0)$ & $0(0.0)$ & \\
\hline & AGC & $0(0.0)$ & $2(50.0)$ & $2(50.0)$ & \\
\hline & Total & $14(7.4)$ & $139(73.6)$ & $36(19.0)$ & \\
\hline & Benign & $12(12.8)$ & $55(58.5)$ & $27(28.7)$ & 0.001 \\
\hline & CINI & $1(2.0)$ & $41(83.7)$ & $7(14.3)$ & \\
\hline \multirow[t]{2}{*}{ Biopsy } & CIN II-III & $1(2.4)$ & $39(92.9)$ & $2(4.8)$ & \\
\hline & Cervical Cancer & $0(0.0)$ & $4(100.0)$ & $0(0.0)$ & \\
\hline
\end{tabular}

*Benign includes normal smear, infection, and atrophy. ASC-US: Atypical Squamous Cells-Undetermined Significance; ASC-H: Atypical Squamous Cells-Can not exclude High grade lesion; LGSIL: Low Grade Squamous Intraepithelial Lesion; HGSIL: High Grade Squamous Intraepithelial Lesion; AGC: Atypical Glandular Cells; CIN: Cervical Intraepithelial Neoplasia.

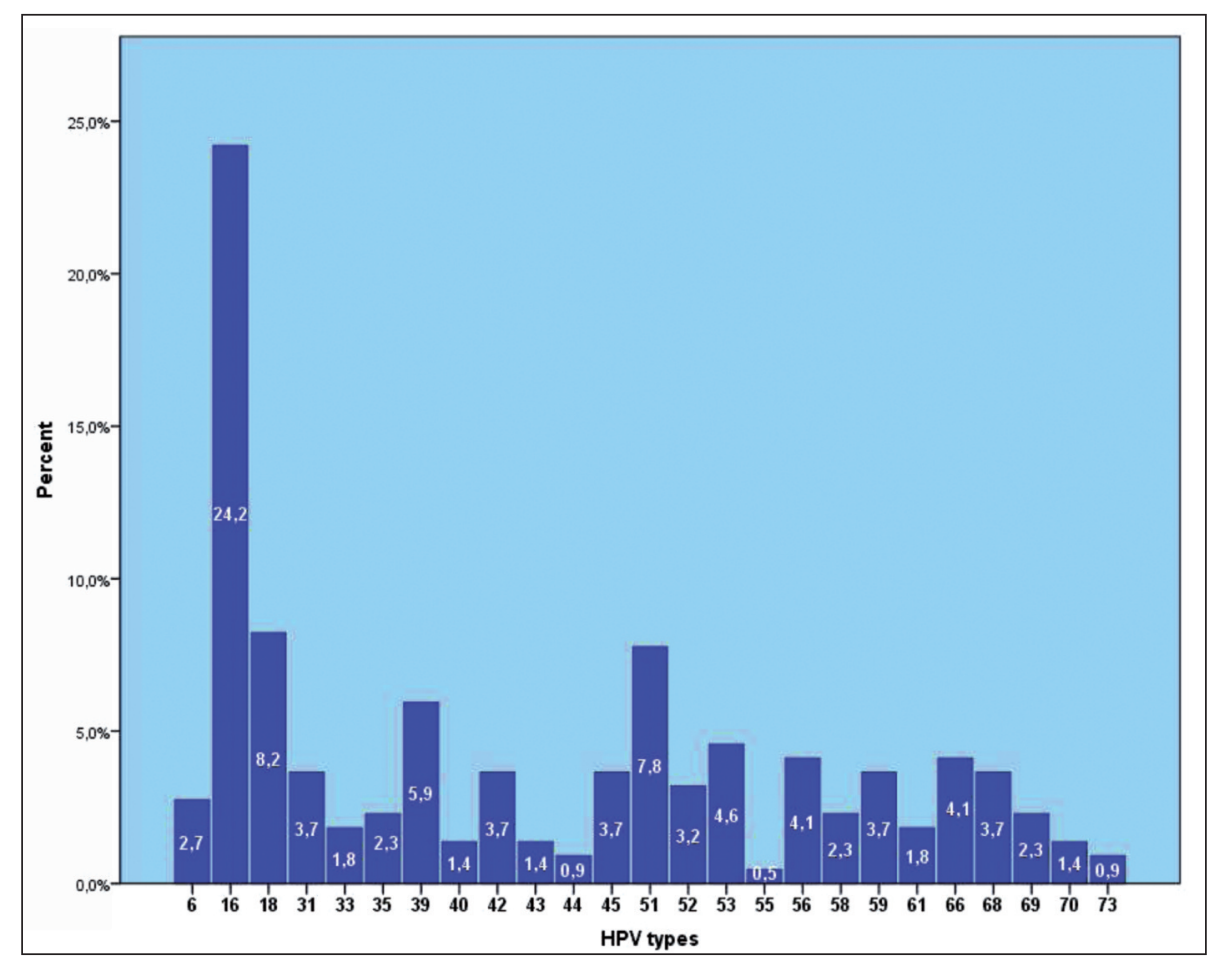

FIGURE 3: The prevalence of different HPV genotypes in 189 patients.

tional Central HPV laboratory. The evaluation of the first 1 million screened women have shown an incidence of HPV positivity as 3.5\% and the most common HPV genotypes in the screened population were HPV 16 followed by HPV 51, 31,52,18. Cytological abnormality was reported in $19.1 \%$ of the cases with HPV positivity. ${ }^{11}$ According to the "Turkey: Human Papillomavirus and Related Dis- eases, Summary Report 2017" data the prevalence of HPV16-18 in normal cytology, low-grade lesions, high-grade lesions and cervical cancer is $4.7 \%, 24.1 \%, 30.2 \%, 67.6 \%$ respectively. ${ }^{12}$ A metaanalysis investigating the world-wide prevalence of HPV reported an estimated prevalence of $10.4 \%$ (95\% CI 10.2-10.7) in women with normal cervical cytology and the estimated by region were given 
TABLE 3: Comparison of the histopathological examination results of the colposcopy guided-biopsies with smear, HPV status and HPV type.

\begin{tabular}{|c|c|c|c|c|c|c|}
\hline & & \multicolumn{4}{|c|}{ Colposcopy-guided biopsy } & \multirow[b]{2}{*}{$\mathrm{p}$} \\
\hline & & Benign $\mathrm{n}(\%)$ & CIN In (\%) & CIN II-III n (\%) & Cervical Cancer n (\%) & \\
\hline & Benign & $25(51.0)$ & $16(32.7)$ & $8(16.3)$ & $0(0.0)$ & $<0.001$ \\
\hline & ASC-US & $40(62.5)$ & $16(25.0)$ & $8(12.5)$ & $0(0.0)$ & \\
\hline & ASC-H & $1(5.6)$ & $0(0.0)$ & $15(83.3)$ & $2(11.1)$ & \\
\hline \multirow[t]{5}{*}{ Smear } & LSIL & $25(50.0)$ & $16(32.0)$ & $9(18.0)$ & $0(0.0)$ & \\
\hline & HSIL & $0(0.0)$ & $0(0.0)$ & $2(50.0)$ & $2(50.0)$ & \\
\hline & AGC & $3(75.0)$ & $1(25.0)$ & $0(0.0)$ & $0(0.0)$ & \\
\hline & Total & $94(49.7)$ & $49(26.0)$ & $42(22.2)$ & $4(2.1)$ & \\
\hline & HPV negative & $27(75.0)$ & $7(19.4)$ & $2(5.6)$ & $0(0.0)$ & $<0.001$ \\
\hline \multirow[t]{2}{*}{ HPV status } & Single HPV & $57(50.8)$ & $34(30.4)$ & $18(16.1)$ & $3(2.7)$ & \\
\hline & $\geq 2 \mathrm{HPV}$ & $10(24.4)$ & $8(19.5)$ & $22(53.7)$ & $1(2.4)$ & \\
\hline \multirow[t]{2}{*}{ HPV Type } & HPV 16-18 & $19(20.2)$ & $17(34.7)$ & $24(57.1)$ & $4(100.0)$ & 0.001 \\
\hline & Other HPV & $48(51.1)$ & $25(51.0)$ & $16(38.1)$ & $0(0.0)$ & \\
\hline
\end{tabular}

ASC-US: Atypical Squamous Cells-Undetermined Significance; ASC-H: Atypical Squamous Cells-Cannot exclude High grade lesion; LGSIL: Low Grade Squamous Intraepithelial Lesion; HGSIL: High Grade Squamous Intraepithelial Lesion; AGC: Atypical Glandular Cells.

as Africa 22.1\% (20.9-23.4), Central America and Mexico 20.4\% (19.3-21.4), northern America $11.3 \%$ (10.6-12.1), Europe $8.1 \%$ (7.8-8.4), and Asia $8.0 \%(7.5-8.4) .{ }^{13}$ In the presented study, all the benign cases were recruited to the study as the patients had shown HPV positivity and the prevalence of oncogenic and non-oncogenic HPV genotypes were $89.8 \%$ and $10.2 \%$ respectively.

In a study that analyzed the prevalence reports published between 2000-2011 overall HPV prevalence was given as $32.1 \%$ (95\% CI 32.098, 32.102) and the significant risk factors for HPV infection were given as first coitus at a younger $(\leq 15)$ age, increased number of pregnancies, increased number of sexual partners, use of contraceptives, smoking and chewing habit and early age at marriage. ${ }^{14}$ However, in the presented study there was no statistically significant difference in the incidence of these risk factors between the patients who had HPV infection and patients who were HPV negative.

HPV infection has a higher prevalence in sexually active young women of 18-30 years of age and the prevalence decreases after the age of 30 . There is a sharp decrease in prevalence after 30 years of age. Depending on various factors most probably due to the oncogenity of the HPV genotype, viral load, immunological status of the patient and coexistance of other sexually transmitted diseases the persistence of the infection will lead to a progression to cancer in some of the HPV positive patients. The progression to cervical cancer is slow. ${ }^{15}$ The estimated number of annual new cervical cancer cases is estimated to be 1868 in Turkey with the highest number cumulated in the 40-64 age group. ${ }^{12}$ A recent study showed that in all world regions, HPV prevalence was highest in women younger than 35 years of age, decreasing in women of older age. In Africa, the Americas, and Europe, a clear second peak of HPV prevalence was observed in women aged 45 years or older. ${ }^{14}$ The patients who had a HPV positivity in our study were in mostly in their fourth decade most probably due to the women's inadequate awareness of the HPV screening and the voluntary nature of the HPV testing. A recent study from Turkey reported similar values as a mean age of the patient group with HPV 16 or 31 positivity was reported to be 42.83 \pm 8 .6, while the mean age of the remaining group with other HPV genotypes was $44.71 \pm 9.34 .^{16}$

In a study from Turkey, Yuce et al screened 890 women and reported that a prevalence of any HPV as $25.7 \%$ while high-risk HPV positivity was 
23.0\%. The most common HPV types was 16 followed by HPV 31 and 51 and $89.5 \%$ of the HPVpositive women had at least one type of high-risk HPV.${ }^{17}$ A hospital-based study that retrospectively analyzed the incidence of HPV genotypes in 5 cities of Turkey reported that the most frequent oncogenic HPV genotypes encountered were HPV-16 (18.9\%), HPV-18 (13.1\%,), HPV- 31 (4.9\%), HPV-33 (3.3\%), HPV-35 (7.49\%), HPV-39 (5.7\%), HPV-45 (5.7\%), HPV-51 (11.5\%). ${ }^{18}$ Polat et al reported that the most prevalent HPV genotypes in women who had normal and abnormal cytology were HPV 16, HPV 6 and HPV 18 respectively in 507 women. ${ }^{19}$ In our patient group the most common HPV genotype was found to be HPV 16 (24.0\%) followed by HPV 18 (8.2\%), HPV 51 (7.8\%), HPV 39 (5.9\%) and HPV 53 (4.6\%). Although the studies from Turkey reported HPV 16 as the most prevalent HPV genotype, the second most prevalent genotype showed variations.

A study from Denmark reported the prevalence of high-risk HPV positivity as $20.6 \%$ among 40382 women who were screened- with the highest incidence encountered in women of 20-23 years old (46.0\%)- while HPV 16 was found to be the most prevalent genotype. CIN III was more frequent when the HPV genotype was present alongside with HPV 16 rather than being a single HPV infection or when it is linked to other high-risk HPV genotypes. ${ }^{20}$ Among the ten most frequent HPV oncogenic types in Turkey among women with invasive cervical cancer by histology, HPV 16 had the highest prevalence (58.4\%) followed by HPV 45 and 18 (9.3\% and 9.2\% respectively). ${ }^{12}$ All four cases who had an invasive cervical carcinoma had HPV16-18 positivity in the presented series. A systemic-review that aimed to analyze the HPVgenotype prevalence in Africa that HPV16/18 was demonstrated in $67.7 \%$ of invasive cervical carcinoma cases while $4.4 \%$ and $2.8 \%$ of women with normal cervical cytology were positive for HPV 16 and 18 respectively. HPV 16 positivity was $12 \%$ in ASC-US, $14.5 \%$ in LSIL, $31.2 \%$ in HSIL while HPV18 positivity was $4.4 \%, 19 \%$ and $13.9 \%$ respectively in the corresponding histopathological lesions. ${ }^{21}$
Kulhan et al recently reported that among the $325 \mathrm{HPV}$-positive women screened, 63.1\% were positive for a single HPV type while the remaining $36.9 \%$ were positive for multiple and the four most prevalent high-risk types were HPV 16, 31, 51 and $52 .{ }^{16}$ In the presented patient group $21.6 \%$ of the 189 patients had more than one HPV genotype positivity. A study from USA reported an incidence of $4.6 \%$ for $\geq 2$ HPV genotype among 74543 women screened and the authors pointed out the possible importance of interaction between the HPV genotypes. ${ }^{22}$ A Canadian study demonstrated that the most common HPV genotype encountered in CIN and invasive carcinoma cases were HPV 16. HPV 16 and 18 accounted for $70.2 \%$ of the invasive cervical cancer cases. The incidence of multiple type infections were higher in women with CIN II in comparison to women with invasive cervical cancer $(61.3 \%$ vs $20.2 \% \mathrm{p}<0.001){ }^{23}$

There was a discrepancy between the cervical cytology report and histopathological examination of the colposcopy-guided biopsies. The CS cytology report of the four invasive cervical cancer patients were ASC-H $(n=2)$ and HGSIL $(n=2)$. The discrepancy between the abnormal cervical cytology and histological findings of the specimen obtained by biopsy is reported by other investigators. ${ }^{24}$ The sensitivity of cervical cytology versus HPV testing as a triage testing has been investigated for different cervical lesions in order to avoid false negative results and unnecessary invasive procedures due to false positive results. ${ }^{25,26}$

There is an ongoing dilemma about the most reliable method that can be used for cervical cancer screening; cervical cytology versus HPV testing. High-risk HPV testing is recommended as an alternative to cervical cytology as a primary screening test while it is recommended to be used as a cotest by different groups. A recent Cochrane review investigated the diagnostic accuracy of HPV testing for detecting histologically confirmed cervical intraepithelial neoplasia by including 40 studies. There is a heterogeneity of the results for different cervical lesions however HPV tests had a higher detection rate of CIN 2+ and CIN 3+ cases while they caused more unnecessary referrals. The au- 
thors concluded that, a negative HPV test is more reassuring for absence of an abnormal lesion than a negative cytological test, as the possibility of having a false negative cytological test was higher. ${ }^{27}$

The limitation of the study is the limited number of patients recruited and the fact that it is not a population-based study. There is a need for further studies with larger number of patients and it will be also interesting to follow-up the cervical changes in patients who have a benign cervical pathology but have oncogenic HPV-positivity.

\section{CONCLUSION}

There appears to be a geographic variation in the distribution of the most prevalent HPV genotypes per region. In this study, the four most prevalent high-risk types were HPV 16, 18, 51 and 39 in our population. It is important to investigate the most prevalent HPV genotypes in the investigated population if HPV genotype testing is going to be used for triage and HPV 16 and HPV18 testing is believed to have a major role in screening for cervical abnormalities. HPV genotype testing is also important in development of HPV vaccines.

\section{Source of Finance}

During this study, no financial or spiritual support was received neither from any pharmaceutical company that has a direct connection with the research subject, nor from a company that provides or produces medical instruments and materials which may negatively affect the evaluation process of this study.

\section{Conflict of Interest}

No conflicts of interest between the authors and / or family members of the scientific and medical committee members or members of the potential conflicts of interest, counseling, expertise, working conditions, share holding and similar situations in any firm.

\section{Authorship Contributions}

Idea/Concept: Mehmet Bülbül, Berna Dilbaz, Esra Boyar; Design: Mehmet Bülbül, Berna Dilbaz, Bilge Aydın Türk; Control/Supervision: Mehmet Bülbül, Berna Dilbaz; Data Collection and/or Processing: Mehmet Bülbül, Berna Dilbaz, Bilge Aydın Türk, Filiz Hatipoğlu, Esra Boyar; Analysis and/or Interpretation: Mehmet Bülbül, Berna Dilbaz, Bilge Aydın Türk, Filiz Hatipoğlu, Esra Boyar; Literature Review: Mehmet Bülbül, Berna Dilbaz, Esra Boyar; Writing the Article: Mehmet Bülbül, Berna Dilbaz; Critical Review: Mehmet Bülbül, Berna Dilbaz.

\section{REFERENCES}

1. Bruni L, Barrionuevo-Rosas L, Albero G, Serrano $B$, Mena $M$, Gómez D, et al. ICO Information Centre on HPV and Cancer (HPV Information Centre). Human Papillomavirus and Related Diseases in the World. Summary Report; 2017. p.322.

2. Ferlay J, Soerjomataram I, Ervik M, Dikshit R, Eser S, Mathers C, et al. GLOBOCAN 2012 v1.0, Cancer Incidence and Mortality Worldwide: IARC CancerBase No. 11 [Internet]. Lyon, France: International Agency for Research on Cancer; 2013. Available from: http://globocan.iarc.fr (access: 4 March 2018.03.04)

3. Saslow D, Solomon D, Lawson HW, Killackey M, Kulasingam SL, Cain J, et al. American Cancer Society, American Society for Colposcopy and Cervical Pathology, and American Society for Clinical Pathology screening guidelines for the prevention and early detection of cervical cancer. J Low Genit Tract Dis 2012;16(3):175-204

4. Walboomers JM, Jacobs MV, Manos MM, Bosch FX, Kummer JA, Shah KV, et al.
Human papillomavirus is a necessary cause of invasive cervical cancer worldwide. J Pathol 1999;189(1):12-9.

5. de Sanjose S, Quint WG, Alemany L, Geraets DT, Klaustermeier JE, Lloveras B, et al. Human papillomavirus genotype attribution in invasive cervical cancer: a retrospective cross-sectional worldwide study. Lancet Oncol 2010;11(11):1048-56.

6. Bosch FX, Lorincz A, Muñoz N, Meijer CJ, Shah KV. The causal relation between human papillomavirus and cervical cancer. J Clin Pathol 2002;55(4):244-65.

7. Stoler MH, Shifman M. Interobserver reproducibility of cervical cytologic and histologic interpretations: realistic estimates from the ASCUS-LSIL Triage Study. JAMA 2001; 285(11):1500-5

8. C Kitchener H, Canfell K, Gilham C, Sargent A, Roberts C, Desai M, et al. The clinical effectiveness and cost-effectiveness of primary human papillomavirus cervical screening in England: extended follow-up of the ARTISTIC randomised trial cohort through three screen- ing rounds. Health Technol Assess 2014; 18(23):1-196.

9. Simms KT, Hall M, Smith MA, Lew JB Hughes S, Yuill S, et al. Optimal management strategies for primary HPV testing for cervical screening: cost-effectiveness evaluation for the national cervical screening program in Australia. PLoS One 2017;12(1)

10. Türkiye İstatistik Kurumu (TÜiK). Yaş Grubu ve Cinsiyete Göre Nüfus; 2017. Available from http://www.tuik.gov.tr/UstMenu.do?metod=te melist. (Access: 4 March 2018.03.04).

11. Gultekin M, Zayifoglu Karaca M, Kucukyildiz I, Dundar S, Boztas G, Semra Turan H, et al. Initial results of population based cervical cancer screening program using HPV testing in one million Turkish women. Int $\mathrm{J}$ Cancer 2018;142(9):1952-8.

12. Bruni L, Barrionuevo-Rosas L, Albero G, Serrano $\mathrm{B}$, Mena $\mathrm{M}$, Gómez D, et al. ICO/IARC Information Centre on HPV and Cancer (HPV Information Centre). Human Papillomavirus and Related Diseases in Turkey. Summary Report; 2017 
13. de Sanjosé S, Diaz M, Castellsagué X, Clifford G, Bruni L, Muñoz N, et al. Worldwide prevalence and genotype distribution of cervical human papillomavirus DNA in women with normal cytology: a meta-analysis. Lancet Infect Dis 2007;7(7):453-9.

14. Vinodhini $K$, Shanmughapriya S, Das BC, Natarajaseenivasan K. Prevalence and risk factors of HPV infection among women from various provinces of the world. Arch Gynecol Obstet 2012;285(3):771-7.

15. Burd EM. Human papillomavirus and cervical cancer. Clin Microbiol Rev 2003;16(1):1-17.

16. Kulhan M, Kulhan NG, Seven $Y$, Nayki UA, Nayki $\mathrm{C}$, Ata $\mathrm{N}$, et al. Estimation of the prevalence and distribution of HPV genotypes and identification of related risk factors among Turkish women. Contemp Oncol (Pozn) 2017;21(3):218-23.

17. Yuce K, Pinar A, Salman MC, Alp A, Sayal B, Dogan $S$, et al. Detection and genotyping of cervical HPV with simultaneous cervical cytology in Turkish women: a hospital-based study. Arch Gynecol Obstet 2012;286(1):203-8.

18. Barut MU, Yildirim E, Kahraman M, Bozkurt M, Imirzalioğlu N, Kubar A, et al. Human papilloma viruses and their genotype distribution in women with high socioeconomic status in
Central Anatolia, Turkey: a pilot study. Med Sci Monit 2018;4(24):58-66.

19. Dursun P, Senger SS, Arslan H, Kuşçu E, Ayhan A. Human papillomavirus (HPV) prevalence and types among Turkish women at a gynecology outpatient unit. BMC Infect Dis 2009;9:191.

20. Kjær SK, Munk C, Junge J, Iftner T. Carcinogenic HPV prevalence and age-specific type distribution in 40,382 women with normal cervical cytology, ASCUS/LSIL, HSIL, or cervical cancer: what is the potential for prevention? Cancer Causes Control 2014;25(2):17989.

21. Ogembo RK, Gona PN, Seymour AJ, Park HS, Bain PA, Maranda L, et al. Prevalence of human papillomavirus genotypes among African women with normal cervical cytology and neoplasia: a systematic review and metaanalysis. PLoS One 2015;10(4):e0122488.

22. Dickson EL, Vogel RI, Bliss RL, Downs LS Jr. Multiple-type HPV infections: a cross-sectional analysis of the prevalence of specific types in 309,000 women referred for HPV testing at the time of cervical cytology. Int J Gynecol Cancer 2013;23(7):1295-302.

23. Coutlée F, Ratnam S, Ramanakumar AV, Insinga RR, Bentley J, Escott N, et al. Distribu- tion of human papillomavirus genotypes in cervical intraepithelial neoplasia and invasive cervical cancer in Canada. J Med Virol 2011;83(6):1034-41.

24. Alanbay I, Öztürk M, Fıratlıgil FB, Karaşahin KE, Yenen MC, Bodur S. Cytohistological discrepancies of cervico-vaginal smears and HPV status. Ginekol Pol 2017;88(5):2358.

25. Cuzick J, Myers O, Lee JH, Shi Y, Gage JC, Hunt WC, et al; New Mexico HPV Pap Registry Steering Committee. Outcomes in women with cytology showing atypical squamous cells of undetermined significance with vs without human papillomavirus testing. JAMA Oncol 2017;3(10):1327-34.

26. Ryu KJ, Lee S, Min KJ, Kim JW, Hong JH, Song JY, et al. Reflex human papillomavirus test results as an option for the management of Korean women with atypical squamous cells cannot exclude high-grade squamous intraepithelial lesion. Oncologist 2015;20(6): 635-9.

27. Koliopoulos G, Nyaga VN, Santesso N, Bryant A, Martin-Hirsch PP, Mustafa RA, et al. Cytology versus HPV testing for cervical cancer screening in the general population. Cochrane Database Syst Rev 2017;8:CD008587. 